\title{
RECUPERACIÓN DEL ARROYO QUIÑONES. DISEÑO DE PARQUE RECREATIVO. MADRID-ESPAÑA
}

\author{
(RECUPERATION OF THE QUIÑONES STREAM. \\ DESIGN OF A RECREATION PARK. MADRID-SPAIN)
}

\author{
Mara Díaz y Maa Antonieta García \\ Delegación de Medio Ambiente del Excmo. Ayuntamiento de San Sebastián de los Reyes.
}

Fecha de recepción: $15-$ IX - 92

\begin{abstract}
RESUMEN
El proyecto de recuperación del Arroyo Quiñones y sus márgenes, que se describe en el presente artículo, trata no sólo del acondicionamiento paisajistico de zonas degradadas, sino también del aprovechamiento del gran potencial recreativo que tiene la zona, situado próximo a espacios de alto valor ecológico como la Dehesa Boyal y el Soto de Viñuelas.

El área de actuación se encuentra en el término municipal de San Sebastián de los Reyes, siendo la Delegación de Medio Ambiente la que ha encargado la realización de este Proyecto, que queda encuadrado en su Programa de Restauración del Medio.

Las actuaciones que se contemplan se agrupan en:

- Acondicionamiento del cauce.

- Diseño de zonas recreativas.

- Revegetación con especies autóctonas y ornamentales.

- Acondicionamiento de caminos.

- Instalación de equipamiento recreativo.
\end{abstract}

\section{SUMMARY}

The project described in this article not only treats the landscape renewal of deteriorated areas of the Quiñones Stream, but also details its great recreative potential resulting from its proximity to the Dehesa Boyal and El Soto de Viñuelas, both ecologically praiseworthy.

The project area is located in the municipal county of San Sebastian de los Reyes, being its environmental protection office the entity requesting the realization of this project as part of its Recover the Environment Program.

The tasks considered in the project can be grouped as follows:

- Recuperation of the streambed.

- Landscape design of recreation areas.

- Revegetation of the area using both native and omamental plants.

- Improvement of the paths.

- Installation of recreation equipment.

\section{Introducción}

El presente Proyecto aborda el problema de la recuperación de terrenos degradados y su acondicionamiento como áreas recreativas. El ámbito periurbano, en el que se sitúa la zona de actuación, sufre una fuerte presión ejercida por la ciudad, lo que acaba deteriorando el medio natural. El objetivo primordial consiste en restaurar satisfaciendo la demanda de zonas verdes existente en el término municipal.

\section{Localización}

Los terrenos a tratar están situados en el término municipal de San Sebastian de los Reyes, a $20 \mathrm{~km}$ de Madrid, y comprenden el cauce y márgenes del Arroyo Quiñones, extendiéndose desde una dehesa municipal, la Dehesa Boyal, hasta $\bar{s} u$ paso por debajo de la carretera Nacional-I (Fig. 1). 


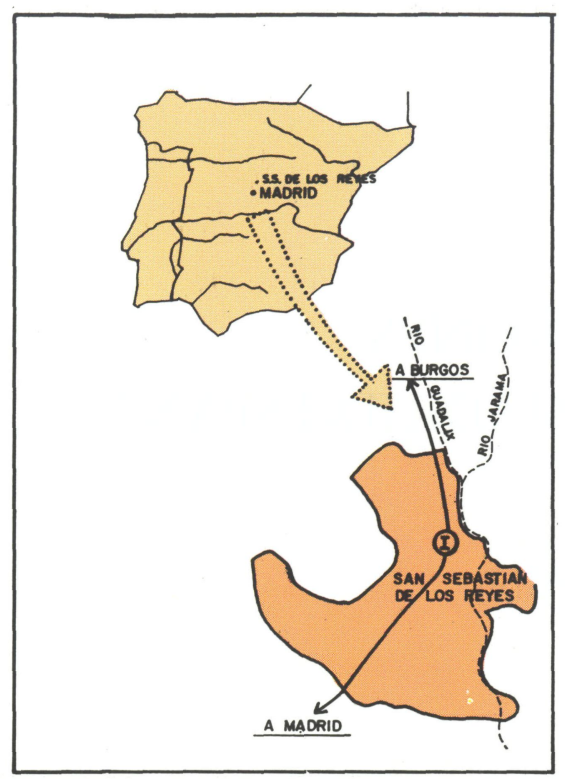

Fig. 1.- Plano de situación.

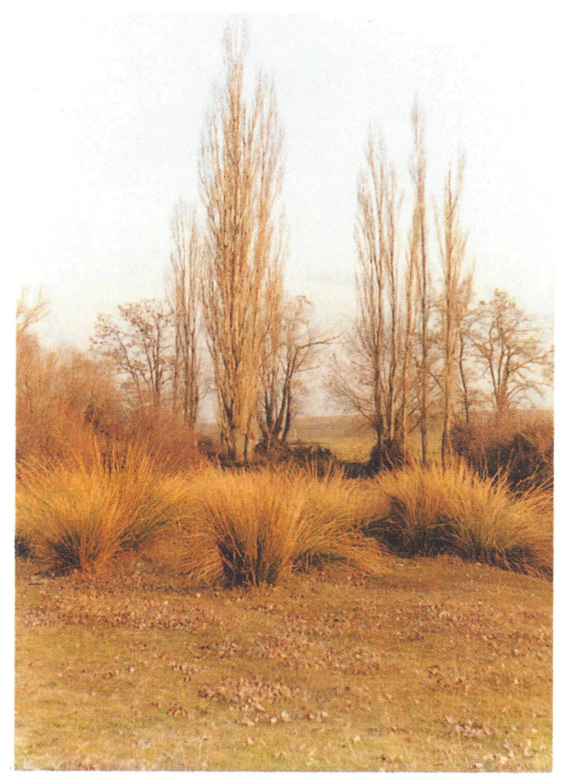

Vegetación autóctona del Arroyo Quiñones.

\section{Objetivos}

Al comienzo del estudio de la zona, se establecieron un conjunto de objetivos básicos a alcanzar con la recuperación:

- Recuperación paisajística. Se pretende preservar los ecosistemas residuales autóctonos; en este caso el ecosistema ripario, y mejorar las características del arroyo mediante la implantación de especies propias de la zona.

- Satisfacción de la demanda de zonas verdes. Se considera que la superficie dedicada a parques y jardines, dentro del término municipal, es insuficiente y es clara la dificultad de crear zonas verdes dentro del casco urbano. Razones por la cuales es del todo ventajoso crear un Parque Periurbano que satisfaga las necesidades de zonas de paseo, merendero, juegos, etc., que existen en el término.

La proximidad de los terrenos a la Dehesa Boyal supondrá una descongestión de la misma, dado que en la actualidad se ve afectada todos los fines de semana por un número excesivo de visitantes.

- Generación de espacios filtro entre el casco urbano y espacios de mayor calidad ecológica, como el Soto de Viñuelas situado al norte del término

municipal, hacia donde se orienta el crecimiento urbano. La creación de una zona verde permitiría una transición gradual entre el ecosistema urbano y el natural.

\section{Problemática}

El problema de mayor entidad es el derivado de la insuficiencia de terrenos disponibles para la creación del Parque. El Ayuntamiento posee sólo la superficie catalogada como zona de dominio público, con la cual, en algunos tramos, es imposible garantizar el paseo por ambas márgenes. Por todo ello se eligieron una serie de zonas en donde establecer las diferentes actividades. La selección de terrenos se hizo considerando los siguientes criterios:

- Elección de terrenos con buena comunicación desde el casco urbano.

- Características físicas propias de la zona que permitan seleccionar terrenos con baja pendiente, poco degradados, alto valor recreativo o ecológicamente frágiles.

- Elección de una zona de enlace entre el polideportivo y el futuro parque.

- Se dio preferencia a terrenos que en la actualidad no se cultivaran.

- Se buscó el máximo distanciamiento posible entre las diferentes áreas para evitar aglomeraciones en ninguna zona. 


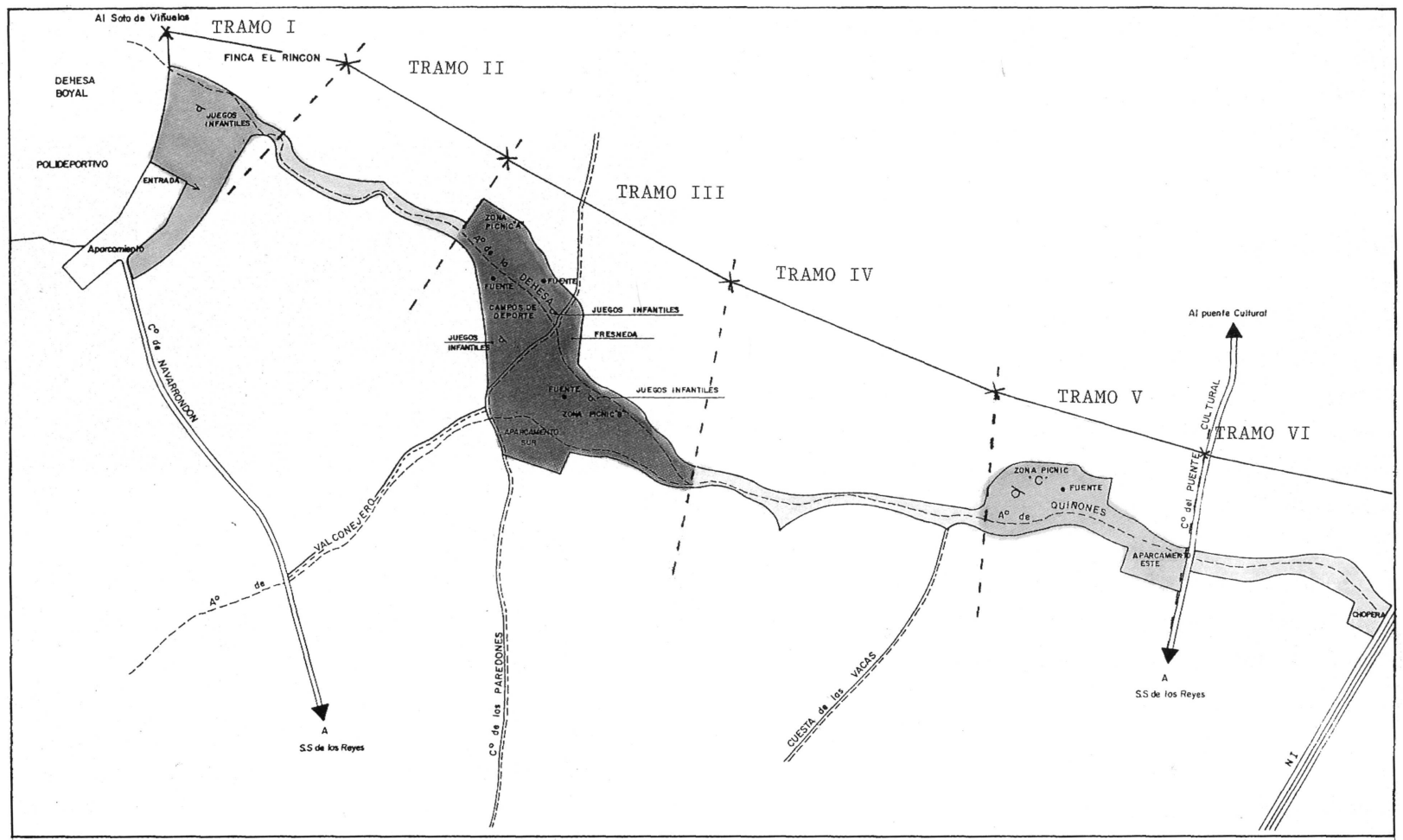

Fig. 2.- Esquema general de los tramos

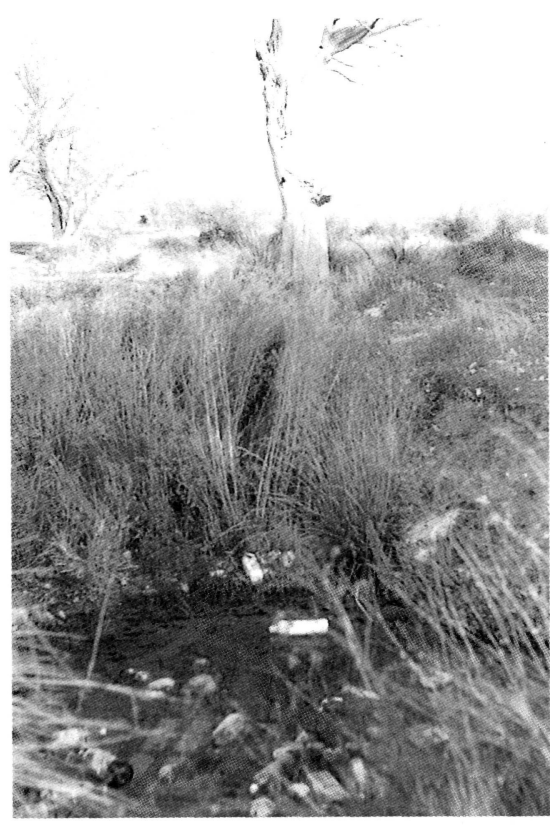

Foto 1

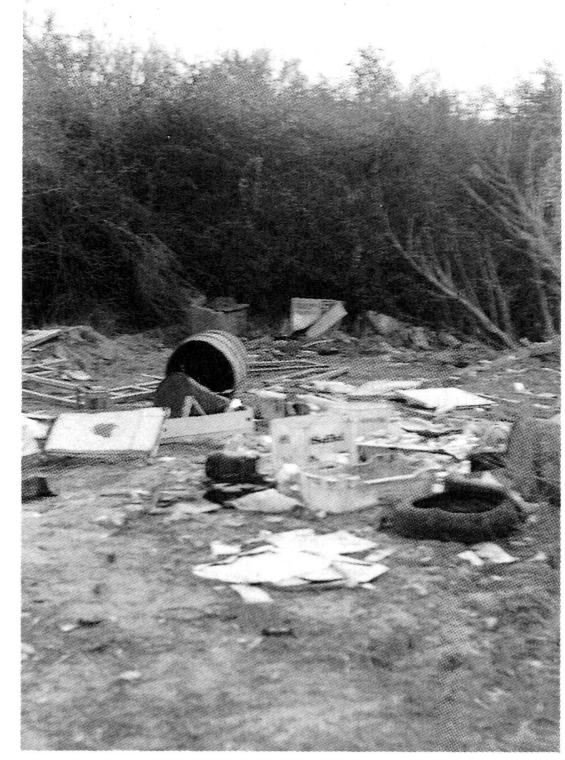

Foto 2
Así es como el Parque de Quiñones se fue perfilando con sus límites Fig. 2.

El estado del cauce es bastante lamentable. En los primeros metros del arroyo, dentro del área de actuación, el cauce carece de agua ya que, excepto en ciertas épocas del año, ésta proviene de los vertidos de aguas residuales del Polideportivo de San
Sebastián de los Reyes, que desembocan a unos 200 metros del inicio del área de actuación.

Los vertidos de efluentes líquidos sin depurar, procedentes de las granjas colindantes en toda la superficie del arroyo, han provocado enç̄arcamientos en donde el acúmulo de basuras inicia procesos de eutrofización (foto 1). 
La utilización del arroyo como vertedero, en donde se depositan áridos, objetos de todo tipo y residuos de materia orgánica, ha provocado que las especies nitrófilas invadan el cauce impidiendo el drenaje de las aguas.

Ambas márgenes están ocupadas, casi en su totalidad, por sendos caminos. Éstos presentan una anchura excesiva y un estado de abandono, casi total, con cárcavas y encharcamientos en los cruces del arroyo con los caminos. En algunos casos el camino está situado en el cauce del arroyo, actuando como dique e impidiendo el drenaje natural de las aguas.

Se puede resumir el estado general por la ausencia de arbolado, excepto en el cauce, y por la abundancia de basuras dispersas por toda la zona (foto 2).

\section{Estudio del medio físico}

El marco físico está determinado por el curso del Arroyo Quiñones, con la vegetación típica de ribera, chopos y sauces principalmente.

Al norte existen alineaciones de cerros de relieve ondulado con laderas de moderada pendiente y ausencia de vegetación de porte arbóreo o arbustivo, estando constituido, fundamentalmente, por campos de cultivo de secano. La pendiente que presentan las laderas hace que disminuya la cuenca visual, impidiendo la visibilidad del Soto de Viñuelas y proporcionando a la zona cierto aislamiento; a esto contribuye también el desarrollo de la vegetación de ribera.

En la zona sur la menor pendiente genera una mayor cuenca visual y permite la visibilidad del casco urbano y otra serie de instalaciones, ya que en general se trata de una zona donde la urbanización es alta. San Sebastián de los Reyes se está extendiendo por esta zona, lo que disminuye su calidad visual, no sólo por el desarrollo de las urbanizaciones, sino también por la proliferación de instalaciones necesarias para la construcción.

Cabe destacar también la existencia de zonas donde se vierten los escombros de una manera incontrolada, generando taludes de pendiente muy elevada e incluso tapando choperas, como ocurre en el área situada cerca de la orilla derecha del arroyo Valconejeros, aproximadamente en la zona de la confluencia de éste con el Arroyo Quiñones. Los

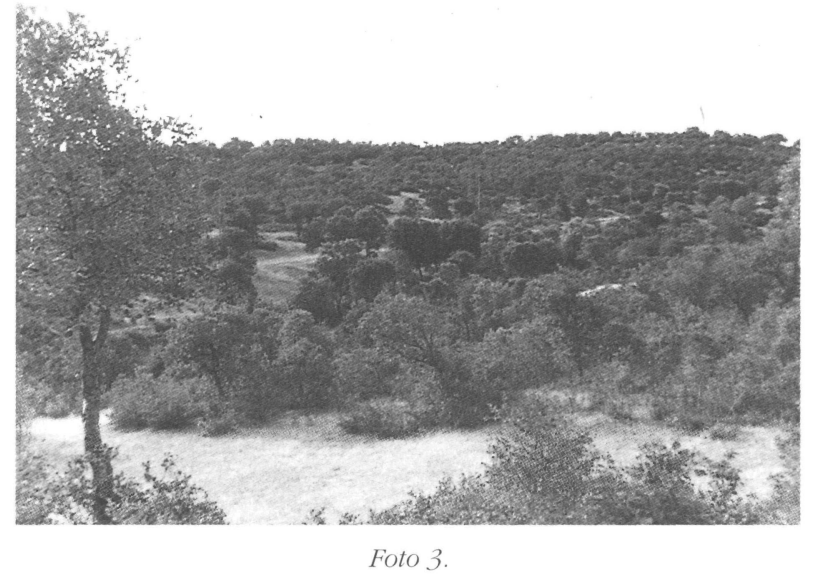

vertidos de efluentes líquidos sin depurar son también una constante.

La presencia de la Dehesa Boyal (foto 3), al noroeste del territorio, aumenta la calidad de las vistas, siendo la única zona verde observable, al quedar el Soto de Viñuelas, enmascarado por las alineaciones de cerros. Ambos espacios son regentados por el Parque Regional de la Cuenca Alta del Manzanares, lo que da idea de su importancia ecológica. Otro dato a tener en cuenta es la cercanía del Polideportivo Municipal que contribuye a aumentar la afluencia de visitantes a la zona.

Al este aparece la carretera Nacional-I cuyos taludes presentan vegetación de porte arbóreo, que actúan como pantalla visual y acústica, aminorando los efectos negativos que supone la visibilidad directa de todo el tráfico y el ruido correspondiente.

El estudio geológico revela la existencia de una plataforma superior del horizonte compuesta por arcosas -un material de alta permeabilidad-.

Los datos de clima reflejan la existencia de un déficit hídrico de $311 \mathrm{~mm}$, lo cual limita las especies a utilizar para la revegetación, aunque hay que tener en cuenta que la presencia del arroyo genera condiciones de mayor humedad.

El estudio bidrogeológico sitúa el nivel freático entre los 20 y $40 \mathrm{~m}$ de profundidad. Este dato determina que la vulnerabilidad a la contaminación del acuífero sea baja, ya que los materiales llegan filtrados.

Los suelos presentan una textura óptima para la retención de agua y sales minerales, sin embargo el contenido en materia orgánica es bajo. 
La vegetación propia de la zona se corresponde con la serie de olmedas y choperas mediterráneas en los lugares próximos al cauce, y con la de la encina y enebrares guadarrámicos en los lugares más alejados. En la actualidad no quedan más que algunos restos de tal vegetación, en el cauce y las lindes de las fincas, ya que fue desplazada por los cultivos de secano los cuales aprovechaban la riqueza edáfica de la zona.

\section{Esquema general del Parque del Arroyo Quiñones}

El Parque propuesto está constituido por una franja de unos $2 \mathrm{~km}$ de longitud con una anchura variable, presentando 3 ensanchamientos, situados dos en los extremos y uno en su zona media (Fig. 2). La zona de actuación quedó dividida en una serie de tramos de la manera siguiente:

\section{Tramo I}

En este tramo el cauce carece de agua. Se actuará sobre una zona situada entre el aparcamiento del Polideportivo Municipal y el cauce. Amplia extensión con buena accesibilidad.

\section{Tramo II}

El arroyo lleva agua procedente de los vertidos sin depurar del Polideportivo. La superficie ocupada por la actuación es la imprescindible para garantizar el paseo por la margen izquierda.

\section{Tramo III}

Comprende los terrenos de mayor importancia en el conjunto del Parque. Se ha compartimentado la superficie dedicándola a diferentes actividades: merendero, deportes informales, juegos infantiles y un aparcamiento.

\section{Tramo IV}

Al igual que el tramo II su función principal es la de dar continuidad al paseo, pero en este caso por ambas márgenes.

\section{Tramo V}

Dado que esta zona tiene buena comunicación con el casco urbano, también se propone instalar una zona de merendero y un aparcamiento.

\section{Tramo VI}

En este tramo se termina el Parque, cerrándose la zona de paseo y acondicionándose una de las zonas más deterioradas.

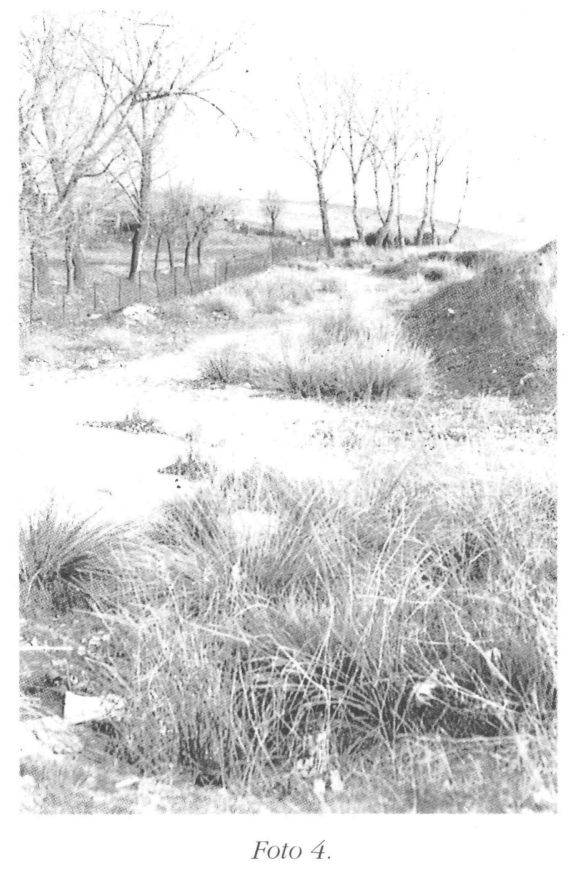

Análisis y diseño de cada tramo

En cada tramo se detalló su actual situación y las actuaciones propuestas encaminadas a resolver su problemática o a desarrollar el diseño previsto, bien fuera funcional o estético.

Tramo I.- El tramo I está situado al este del polideportivo y próximo a la Dehesa Boyal. La entrada principal al Parque de Quiñones se sitúa contigua al aparcamiento del polideportivo debido al deseo de ampliar la zona verde que hoy es la Dehesa Boyal, hacia terrenos menos frágiles y no tan susceptibles de degradación como son los cultivos de secano en zonas llanas o en pendientes suaves. El tramo I es pues un enlace entre la Dehesa y el Parque de Quiñones, y entre el polideportivo, con su deporte estructurado, y un parque rural, abierto a juegos informales, al paseo, y a la merienda campestre (Fig. 2).

La situación actual del tramo I es la siguiente:

1) Inexistencia de agua en el arroyo, ni de una caja por donde discurriría el agua en caso de avenida (foto 4).

2) Obstrucción con basuras y escombros del tubo de desagüe, donde atraviesa el arroyo por debajo del Cํ de Navarrondón.

3) Basuras dispersas por todo el tramo. =

4) Inexistencia de vegetación arbórea y arbustiva. 
5) Acceso de vehículos por el camino perpendicular al Co de Navarrondón.

6) Vistas poco atractivas de la ciudad, polígono industrial y fincas con instalaciones deterioradas.

7) Vertido de arenas en el arroyo para permitir el paso de vehículos.

8) Taludes con pendientes pronunciadas.

9) Existencia de zanjas con basuras.

Las actuaciones propuestas en este tramo son las siguientes:

1) Limpieza y acondicionamiento del tubo de desagüe del Co de Navarrondón.

2) Excavación de una franja de tierra que actúe como caja del arroyo.

3) Limpieza manual de basuras.

4) Revegetación tanto con especies de secano como de ribera.

5) Remodelado de taludes.

6) Instalación de vallas protectoras en las entradas de los caminos peatonales y de un cerramiento rústico bordeando el límite del aparcamiento con el parque.

7) Creación de caminos peatonales.

8) Instalación de mobiliario urbano como pueden ser: bancos, juegos infantiles, papeleras y paneles informativos.

9) Acondicionamiento de caminos existentes.

10) Encachado del cruce entre el camino y el arroyo.

La selección y distribución de la vegetación en este tramo, al igual que en el resto de los tramos, es la base del diseño. Las especies de secano: el pino piñonero, tomillo, lavanda, romero, encina y almendro se han elegido, en la explanada más alejada del arroyo y próxima al aparcamiento, para proporcionar sombra, formar barreras visuales hacia vistas poco estéticas, actuar como límites naturales del parque en zonas sin cerramiento, proporcionar color y olor en zonas de estancia y para abaratar los costes de riego y mantenimiento durante todo el año.
Más próximos al arroyo se eligieron especies de ribera tales como el sauce y el chopo, mientras que en las zonas de juegos infantiles o zonas de reposo se han optado por especies de gran porte como arces y álamos para proporcionar sombra. Se prevé una recuperación de la pradera natural con especies de gramíneas y herbáceas, ya existentes en la zona.

Los caminos peatonales de tierra compactada enlazan las entradas al parque con los caminos principales, que actualmente ya existen, ensanchándose ahí donde se prevé aglomeraciones, como en las entradas, alrededor de los paneles informativos y en las zonas próximas a los juegos infantiles.

Tramo II.- Este tramo es una franja visualmente aislada del casco urbano por la espesa vegetación de ribera existente. Es una zona de recreo pasivo: el paseo, el descanso, la lectura.

El principal problema que caracteriza este tramo y que se repite a lo largo de todo el Parque es la aparición de los vertidos del polideportivo. Estas aguas desembocan al inicio del tramo II ocasionando un gran desarrollo de la vegetación nitrófila, zarzas y rosas principalmente, debido a la gran cantidad de materia orgánica que presenta la zona del cauce.

Consideramos necesario eliminar esta vegetación para posibilitar el drenaje de las aguas. El método óptimo habría sido el manual, puesto que la selectividad con que se realiza la eliminación de la vegetación es mayor, pero la densidad de la flora era tal que se optó por un proceso mecánico. Se eliminará la vegetación en los $3 \mathrm{~m}$ de cauce, respetando aquellos ejemplares que tengan un diámetro igual o mayor de $15 \mathrm{~cm}$.

Tramo III.- Se eligió esta zona triangular en la confluencia de los 2 arroyos para concentrar unas actividades recreativas por una serie de razones:

1) Tiene fácil acceso desde la ciudad por el $C^{o}$ de Paredones. 2) La zona es amplia, el relieve llano y el suelo franco-arenoso tiene buen drenaje. 3) El microclima aquí es más fresco en verano que en el resto de las zonas. 4) Existe una zona de pendiente suave apta para la instalación de un aparcamiento, dado que el que existe en el polideportivo queda a más de $1 \mathrm{~km}$ de distancia.

Los terrenos eligidos tienen distintas características para proporcionar una cierta diversidad a la zona. Existen zonas en ladera y aisladas por la vegetación 
de ribera; terrenos llanos y amplios, más propios para campos deportivos; y una pradera natural entre los dos arroyos que se consideró óptima para la ubicación de merendero y juegos infantiles.

La situación actual de este tramo es la siguiente:

1) Existen basuras, escombros y vertidos residuales en ambos cauces.

2) Ausencia de vegetación arbórea que proporcione sombra.

3) El Co de Paredones se encuentra en un estado deplorable con cárcavas y depresiones en toda su longitud.

4) Se ha creado un problema por el acceso de vehículos a las fincas vecinas.

5) Existen encharcamientos, tanto en depresiones paralelas al $\mathrm{A}^{\mathrm{o}}$ de Valconejeros como en los cruces del $\mathrm{C}^{\mathrm{o}}$ de Paredones con ambos arroyos.

6) La vegetación arbustiva, principalmente las zarzas, invade los dos arroyos.

Las actuaciones propuestas son las siguientes:

1) Limpieza manual de basuras y vertidos.

2) Recomendación de instalación de fosas sépticas en las fincas con vertidos residuales.

3) Desbroce mecánico de la vegetación del cauce.

4) Implantar vegetación arbórea de ribera, especialmente autóctona.

5) Acondicionamiento de los caminos mediante nivelación y compactación.

6) Relleno de zanjas encharcadas con material sobrante de otras actuaciones.

7) Instalación de vallas protectoras en las entradas de los caminos peatonales, y de un cerramiento rústico en ambos lados del $\mathrm{C}^{\mathrm{o}}$ de Paredones.

El diseño de este tramo se basa, como en el tramo I, en la selección y distribución de las especies vegetales. Éstas se han elegido para poder soportar tanto las temperaturas mínimas, como las máximas, y ésas que solamente requieran los primeros riegos. Se eligieron casi todas de hoja caduca, para permitir la utilización de las

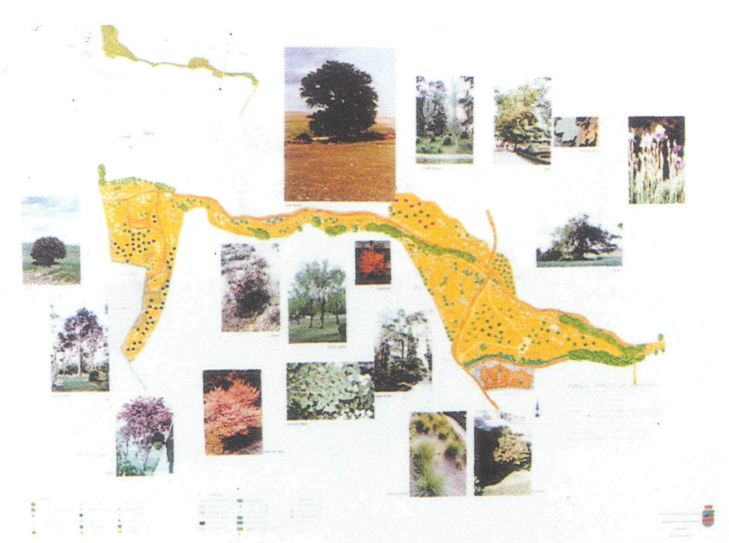

Foto 5.- Propuesta Parque Arroyo Quiñones. Ampliación tramo III - Equipamiento.

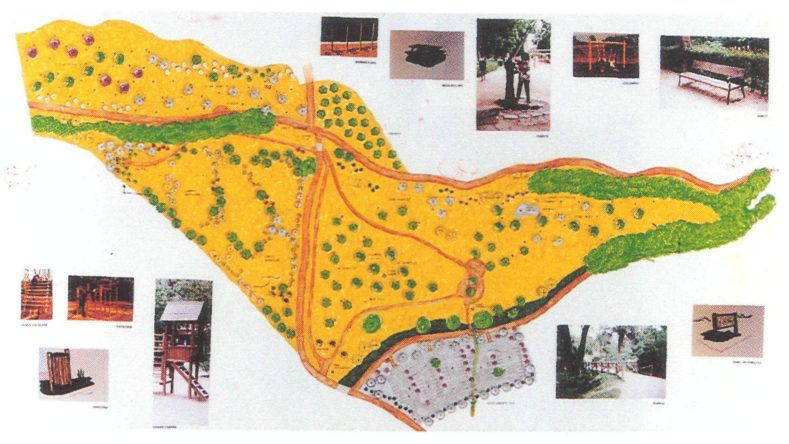

Foto 6.- Propuesta Parque Quiñones. Tramo I - III.

zonas durante todo el año. Se pretende que cumplan tanto un papel funcional, como que formen parte de una experiencia visual de colores estacionales (foto 5).

La vegetación tendría las siguientes funciones en este tramo:

1) Proporcionar sombra.

2) Dividir grandes zonas de juegos.

3) Actuar como barreras protectoras en áreas próximas a los caminos con circulación de coches.

4) Formar barreras visuales de vistas poco estéticas.

5) Estabilizar los taludes del Arroyo de Valconejeros.

6) Proporcionar color estacional.

El tramo III se ha dividido en las siguientes zonas de actuación (foto 6). 


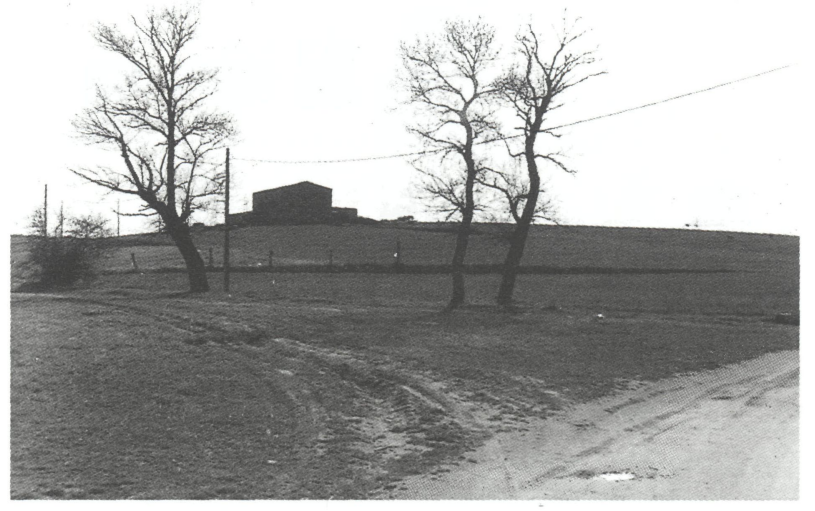

Foto 7

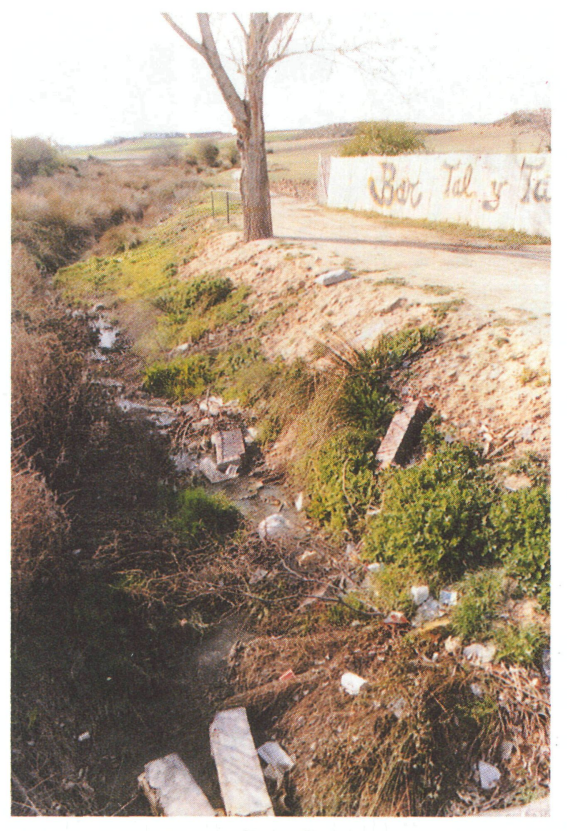

Foto 8

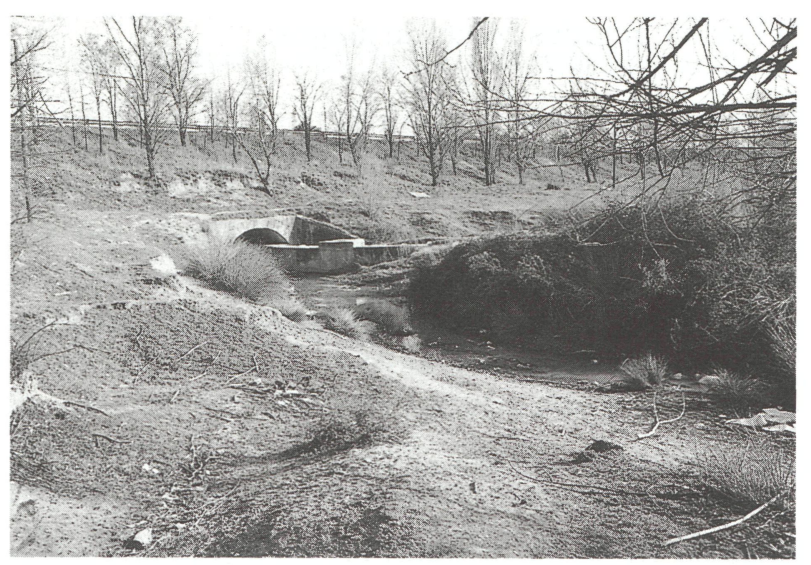

Foto 9
1) Los campos deportivos en espacios irregulares divididos por la vegetación.

2) Las zonas de merendero, en ladera, cerca del arroyo, con más o menos sombra, aisladas o cerca de los juegos infantiles.

3) Los juegos infantiles, de madera, para su mayor integración en el paisaje.

4) El suelo del aparcamiento es de gravilla sobre terreno compactado, donde previamente se ha quitado la capa de tierra vegetal para un posterior aprovechamiento.

5) Los caminos peatonales de $2 \mathrm{~m}$ de anchura se han creado ahí donde se prevé un mayor tránsito de visitantes.

Algunos de los problemas existentes en el tramo III se repiten en el resto de los tramos, y se emplearán las mismas soluciones.

Tramo IV.- El tramo IV se considera semejante al tramo II porque une 2 zonas amplias de mucha infraestructura, y porque tienen las mismas tareas de:

- Adecuación de caminos (foto 7).

- Revegetación con especies de ribera.

- Desbroce de la vegetación en el cauce.

- Limpieza manual.

- Remodelación y revegetación de los taludes del arroyo.

Sin embargo, en el tramo IV se ha decidido adecentar los caminos en ambos lados del arroyo, ya que actualmente existen y se utilizan.

Tramo V.- El tramo V se sitúa entre el Co del Puente Cultural y el tramo IV. Se incluyó para facilitar otro acceso al Parque y con el propósito de descongestionar las zonas recreativas cerca del Polideportivo y la Dehesa Boyal.

Primero se buscó una zona llana, de pendiente mínima, y próxima al Co del Puente Cultural para situar un aparcamiento. A continuación se localizaron unas fincas, a menos de $300 \mathrm{~m}$ de distancia, amplias y con pendientes inferiores al 5\% para la instalación de una zona de merendero y de juegos infantiles.

La situación actual del tramo es la siguiente: 
1) Existe una falta de arbolado.

2) Es necesario facilitar el cruce de un lado del arroyo al otro.

3) Existen escombros y basuras en el cauce (foto 8).

Estos problemas se resolvieron con las siguientes actuaciones:

1) Revegetación. En la zona de merendero se propone la revegetación con especies propias de secano tales como almendros, romero y lavanda. Más cerca del arroyo se proponen variedades de salix, populus y la vegetación actual del cauce, compuesta por typhas y juncos.

2) Pasarela peatonal. El cruce del arroyo se resolverá con una pasarela de pino, apoyada sobre mampostería de granito.

3) Se adecentará el cauce con actuaciones de limpieza, remodelado de taludes y revegetación.

4) Se prevé la instalación de juegos infantiles, mesas-merendero, papeleras, un arenero y una fuente de agua potable cuyo abastecimiento vendría del ramal del $\mathrm{C}^{\mathrm{o}}$ de Navarrondón. El aparcamiento previsto tendrá su entrada y salida por el $\mathrm{C}^{\circ}$ del Puente Cultural, y se prevén plazas para 75 coches. El "apantallamiento" se realizará con especies de populus aligustre y prunus pissardii.

Tramo VI.- El tramo VI empieza en el Co del Puente Cultural y termina en la Nacional-I. Este tramo se ha incluido con el fin de recuperar una zona degradada, y permitir el paseo hasta que el arroyo desagua por una tubería bajo la Nacional-I.

Las actuaciones propuestas en este tramo son iguales a las de los tramos anteriores. Sin embargo, existen 4 problemas no comunes a los otros tramos pendientes de resolver:

1) Existe una escombrera muy larga, la cual habrá que remodelar, cubrir de tierra vegetal, sembrar y revegetar con Salix sp. y vegetación palustre.

2) Desaguan unos colectores al arroyo que se encuentran sucios y desenterrados, y que habría que cubrir con especies trepadoras como madreselva..., y disimular con otras plantas propias de ribera.

(c) Consejo Superior de Investigaciones Científicas Licencia Creative Commons 3.0 España (by-nc)
3) Para permitir la continuidad del paseo se deben unir los dos lados del arroyo. Sin embargo, al ensancharse el arroyo al final del tramo, no se considera estética la instalación de una pasarela peatonal, y se ha decidido unir los caminos por encima del tubo de desagüe, donde actualmente existe un pequeño camino. Aquí se instalaría una valla protectora, se ampliaría el camino a $2 \mathrm{~m}$ y se construiría un muro de contención para sujetar las tierras del talud de la Nacional-I (foto 9).

4) Finalmente se aprovecharía una explanada al final del tramo, para la plantación de una chopera que actúe como barrera visual y acústica de la carretera. Con esta chopera se crearía un punto de referencia en el horizonte que se asociaría con el Parque del Arroyo de Quiñones.

\section{Recomendaciones}

Por último se establece en el proyecto un conjunto de recomendaciones:

Toda ciudad debe tener un límite entre lo que se considera urbano y rústico. Si no lo hubiera, correría el riesgo de que se vayan creando unos límites sin planificación alguna, dejando desprotegidas zonas de valor ecológico y paisajístico. Puede existir una interfase entre lo urbano y lo rural que, en este caso, sería un parque como el que proponemos.

San Sebastián de los Reyes ya tiene un claro límite de su crecimiento al norte, y proponemos las siguientes actuaciones encaminadas a conseguir una mejora ecológica y paisajística:

- Restauración de la superficie que queda comprendida entre el Arroyo de Quiñones y el Soto de Viñuelas, actualmente erosionado y compactado, con el fin de proporcionar al municipio una amplia zona verde, que podría satisfacer la demanda que existe en el municipio de este tipo de áreas.

- Acondicionamiento de los terrenos existentes entre el Polideportivo y la zona de confluencia de los Arroyos Quiñones y Valconejeros. Una posible actuación consistiría en la revegetación de la zona con matorral y especies arbustiva o arbórea que favoreciesen la aparición de Fa encina. Intentando, de esta forma, recuperar lās condiciones naturales del medio. 
- El área de actuación del Proyecto se ha visto limitada en el espacio, pero es fácilmente imaginable pensar en la necesidad de ampliar la recuperación del cauce del Arroyo Quiñones desde su nacimiento, en el Cerro de Otero, hasta su desembocadura en el Jarama. Esta recomendación se hace extensible al Arroyo Valconejero.

- El Ayuntamiento deberá ocuparse de evitar que desde las fincas se expulsen vertidos a los cauces sin ningún tratamiento de sus aguas, obligándoles a crear fosas sépticas cuando no exista otra posibilidad.

- Se recomienda enlazar el Parque de Quiñones con el de la Marina mediante una serie de zonas verdes encaminadas a facilitar el paseo, el ejercicio o el deporte.
- La existencia de un "Taller" de la Naturaleza en el Polideportivo del municipio posibilitaría el establecimiento de una senda ecológica que recorriera las áreas de especial interés de la zona, para acercar a los visitantes al conocimiento de la flora y fauna del lugar.

\section{Conclusiones}

El presente proyecto cobra sentido dentro del marco de actuaciones encaminadas a crear una amplia franja periurbana, de forma que la conservación de la vida silvestre sea compatible con el uso recreativo. La vegetación se considera el elemento principal de la recuperación, intentando utilizar las especies autóctonas fáciles de mantenimiento y poco exigentes, y procurando utilizar especies distintas tratando de conseguir una mayor diversidad e integración en el entorno.

\section{publicación del ICCT/CSIC}

\section{RESTAURACIÓN Y CONSERVACIÓN DE MONUMENTOS}

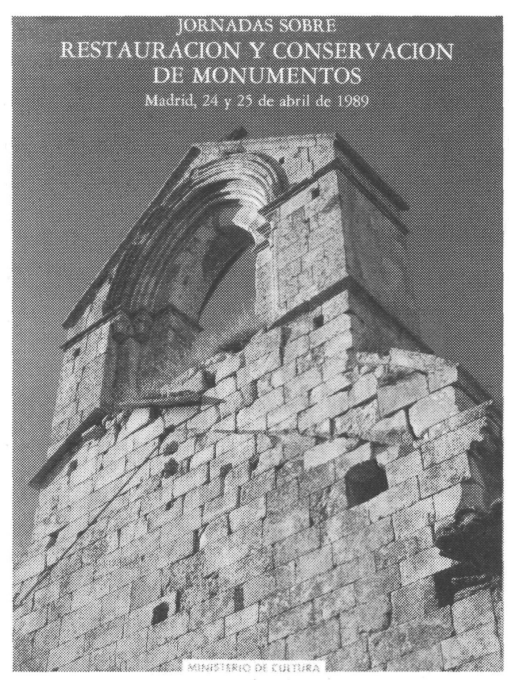

Esta publicación recoge las ponencias e intervenciones presentadas en las Jornadas sobre Restauración y Conservación de Monumentos, celebradas en el Instituto Eduardo Torroja en colaboración con el Instituto de Con. servación y Restauración de Bienes Culturales, y cuyo interés y vigencia hacen de esta obra un valioso instrumento de consulta para los profesionales interesados en la temática de la conservación y restauración del Patrimonio artístico y cultural.

Un volumen de $19,5 \times 21 \mathrm{~cm}$, 204 págs., con numerosas fotografías en color, figuras de línea, gráficos, tablas, etc.

Madrid, 1991.

Existencia limitada de ejem plares.

\section{Indice}

- Prólogo. Antonio Mas-Guindal Latarga ...

Conclusiones.

Presentación. Fernando Aguirre de Yraola

- El Patrimonio Cultural como método cienti
fico. Antonio Majs-Guindal Lafarga a LA PIEDRA. (Porradilla) ....

- Mecanismos de alterción en materiales - Mecanismos de alteración en materiales $p$ -
treos. M. Angeles Vicente ...... - Deterioro de materiales perteos por microor-
ganismos. Cessireo Saiz Jimenez . Métodos de diagnosis - Aplicación de los ensayos fisico-mecánicos

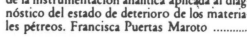

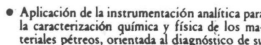

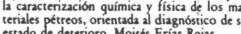

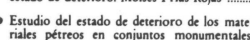
Maria Pilar Luxan ..........

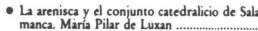

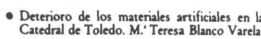

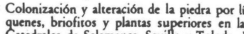
Catedrales de Salamancas sevilina y Toledo.
Garcia Rowe y C. Saiz Jimenez ........

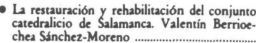
Materiales de Reparación
- Materiales de reparación: sus mecanismos de
actuación y criterios de selección (limpiezza

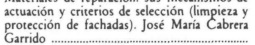

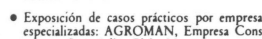
especializadas: AGROMAN Empresa Cons
tructor, S. A. Juliain Pleite Martin -

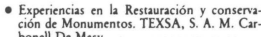
33 bonell De Masy .......... . . . . . . . Mecanismo de degradación

- El Patrimonio construido con tierra necesided de su preservación. Julián Salas .... necessien Metodos de Diagnosis y Ensayo - Consolidación, mejora y nuevas técnicas de - La Muralla de Niebla (Huelva). Ismael Guar- Rechbilitación del Casilloo de Toral de loo
Guzmanes de León. Mariano Vizquez y Elog Algorri ............

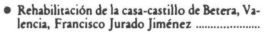
- Actuaciones recomendables en restauraciónes
de edfificos antiguos. Gabriel López Collado

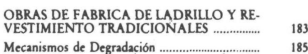
- Eflorescencias. José Garralón Jorba .............. 11 Metodos de Eriggnosis y ensyyo …….......... 191

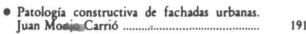
${ }_{81}$ - Metrodos de celiminarción de humedades por ca- 